\title{
Quantitative Analysis of Electrophoresis Data - Application to Sequence-Specific Ultrasonic Cleavage of DNA
}

\author{
Sergei Grokhovsky et al. ${ }^{*}$ \\ Engelhardt Institute of Molecular Biology, Russian Academy of Sciences, Moscow, \\ Russia
}

\section{Introduction}

The complete genomes of many different species are now being revealed in ever increasing pace. The impressive progress made in genome sequencing was largely attributed to development of high resolution denaturing polyacrylamide gel electrophoresis (PAGE). Next-generation sequencing platforms use new powerful technologies, providing gigabases of genetic information in a single run (Farias-Hesson et al., 2010). Nevertheless, scientific research often deals with situations when one needs to change the experimental conditions or the data analysis protocols, but commercial available devices and programs don't give such an opportunity. We have faced this problem during the research focused on the phenomenon of sequence specific ultrasonic cleavage of double-stranded (ds) DNA (Grokhovsky, 2006). The observed sequence dependence of DNA cleavage efficiency was quite surprising. It seems that sequence-specificity of ultrasonic cleavage reflects the local variations in DNA structural dynamics. Thus, ultrasound may provide a basis for developing a new method for studying sequence effects on local structural dynamics of DNA fragments.

It is generally accepted that recognition of various DNA binding sites by many types of transcription factors depends not only on the base pair sequence, but also on local variations in structural parameters of the DNA molecule. Among the important factors involved in these processes are conformational flexibility of sugar-phosphate backbone, geometry of DNA grooves and local bending propensities of the double helix.

Local conformational parameters of DNA are sequence-dependent but in many cases different DNA sequences might carry similar structural profiles (Travers, 2004; Parker et al., 2009). Besides, structural parameters of DNA are sensitive to temperature, ionic strength,

\footnotetext{
" Irina Il'icheva1, Dmitry Nechipurenko², Michail Golovkin², Georgy Taranov²,

Larisa Panchenko ${ }^{3}$, Robert Polozov ${ }^{4}$ and Yury Nechipurenko ${ }^{1}$

${ }^{1}$ Engelhardt Institute of Molecular Biology, Russian Academy of Sciences, Moscow Russia

${ }^{2}$ Department of Physics, Moscow State University, Moscow, Russia

${ }^{3}$ Department of Biology, Moscow State University, Moscow, Russia

${ }^{4}$ Institute of Theoretical and Experimental Biophysics Russian Academy of Sciences, Puschino, Russia
} 
$\mathrm{pH}$ and other factors and might also drastically change in presence of closely bound proteins and other ligands (Neidle et al., 1987; Belikov et al., 2005; Wells, 2009). Structural information for short double-stranded oligonucleotides have been obtained by various experimental methods, including crystal structure data sets (Olson et al., 1998; Sims \& Kim, 2003; Svozil et al., 2008), NMR, and Fourier transform infrared and Raman spectroscopy (Heddi et al., 2010; Abi-Ghanem et al., 2010).

Nevertheless, elucidation of sequence effects on conformation and dynamics of longer DNA fragments remains a challenge. Hence, the development of new methods which would allow studing local structural properties in long double-stranded DNA fragments of several hundreds base pairs is of great importance. Currently there are some methods available for studying sequence-specific variations of DNA flexibility and grooves width along DNA fragments exceeding 100 base pairs in length. These methods are based on the analysis of DNA cleavage produced by various types of agents and irradiations. Cleavages with DNase I (Waring, 2006; Bullwinkle \& Koudelka, 2011), hydroxyl radicals (Tullius, 1988; Van Dyke \& Dervan, 1983) and laser (Spassky \& Angelov, 1997; Vtyurina et al., 2011) or X-ray irradiation (Zubarev \& Grokhovsky, 1991) are typically used for these type of research.

The analysis of sequence-specific DNA cleavage is performed by PAGE. Cleavage patterns obtained by PAGE are further analyzed in order to correlate bands intensities with cleavage efficiencies of corresponding covalent bonds. Variations in cleavage intensities along DNA are attributed to heterogeneity of local structural parameters of the molecule. For example, DNase I-cleavage is sensitive to the geometry of the minor groove and the DNA stiffness that resists bending towards major groove. Thus, variations of phosphodiester bonds cutting efficiencies by DNase I reflect heterogeneity of these parameters along DNA (Hogan et al., 1989; Brukner et al., 1995).

Recently we have developed a new method for studying sequence-dependent structural dynamics of extended DNA fragments (Grokhovsky, 2006, Il'icheva et al., 2009, Nechipurenko et al., 2009). The approach is based on the analysis of ultrasound - induced DNA cleavage using PAGE. Sequence-specificity of ultrasonic cleavage of DNA is attributed to variations in local conformational flexibility of the sugar-phosphate backbone along the irradiated fragments (Grokhovsky et al., 2011). Data produced by this method is complementary to the information recovered using chemically- and DNase I-induced cleavage since ultrasonic cleavage represents a mechanochemical reaction and depends on the local dynamical properties of the DNA molecule.

Using ultrasonic cleavage patterns of DNA by PAGE we show various effects which should be considered during the analysis of the electrophoresis data. In this chapter we will focus on the developed protocols for gel data treatment that helped us to quantitatively describe the observed phenomenon of sequence-specific ultrasonic cleavage of DNA. These methods can be used for the analysis of electrophoresis data obtained during various types of experiments.

\section{Methods and experimental protocols}

In order to address the sequence dependence of the DNA cleavage with different agents, fragments containing a radioactive or fluorescence label at $5^{\prime}$ - or $3^{\prime}$-end of one of the DNA strands are commonly used. We used intense ultrasound treatment of fragments containing 
a radioactive label at the $3^{\prime}$-end of one of the DNA strands. Restriction fragments of DNA were generated by digestion of plasmid DNA by the restriction endonucleases. The fragments were $3^{\prime}$-end-labeled with $[\alpha-32 \mathrm{P}] \mathrm{dATP}$ in the presence of the unlabeled other $\mathrm{dNTP}$ and the Klenow fragment of Escherichia coli DNA-polymerase I. The DNA fragments were isolated by nondenaturing polyacrylamide gel in a 1-mm thick $5 \%$ gel with subsequent elution and precipitation (Maniatis et al., 1982).

\subsection{Sonication of DNA fragments}

For sonication, $10 \mu \mathrm{L}$ of DNA fragments $\left(\sim 10^{4} \mathrm{~Bq}\right)$ in water were mixed with $10 \mu \mathrm{L}$ of $0.2 \mathrm{M}$ NaOAc, $\mathrm{pH}$ 6.0, in the bottom of a thin-walled polypropylene microcentrifuge tube of $0.2 \mathrm{~mL}$ capacity. The final concentration of the fragments was $5-10 \mu \mathrm{g} / \mathrm{mL}(\sim 10 \mu \mathrm{M}$ base pair). The test-tube ends were located $\sim 0.5 \mathrm{~cm}$ below the horn sonicator edge, which had a diameter of 12 $\mathrm{mm}$. The ring and horn sonicator were placed in a vessel with water and crushed ice (Fig.1). Ultrasound was generated by a $300 \mathrm{~W}$ generator with a frequency of 44 or $22 \mathrm{kHz}$ using the maximum power output. The sonication was adjusted in continuous operation mode at 1-min intervals, and after each interval the ring was turned $180^{\circ}$ and fresh ice was added. The ultrasonic power exerted on the system was determined calorimetrically and exceeded $60 \mathrm{~W}$. To obtain rough measurements of the chemical effects induced by cavitation inside the tubes, we used a test tube containing $0.05 \mathrm{M} \mathrm{KI}$ in $0.025 \%$ starch solution. After 8 min of irradiation, the coloration extent was equal to that obtained by adding $\sim 0.1 \mathrm{mM}$ of hydrogen peroxide. This yield is comparable to reported results obtained under normal temperature conditions and with ultrasound intensity exceeding $2 \mathrm{~W} / \mathrm{cm}^{2}$ (Margulis, 1984). It is worth noting that both low ultrasound frequency and low temperature conditions are known to increase the power of cavitational effects (Basedow \& Ebert, 1977).
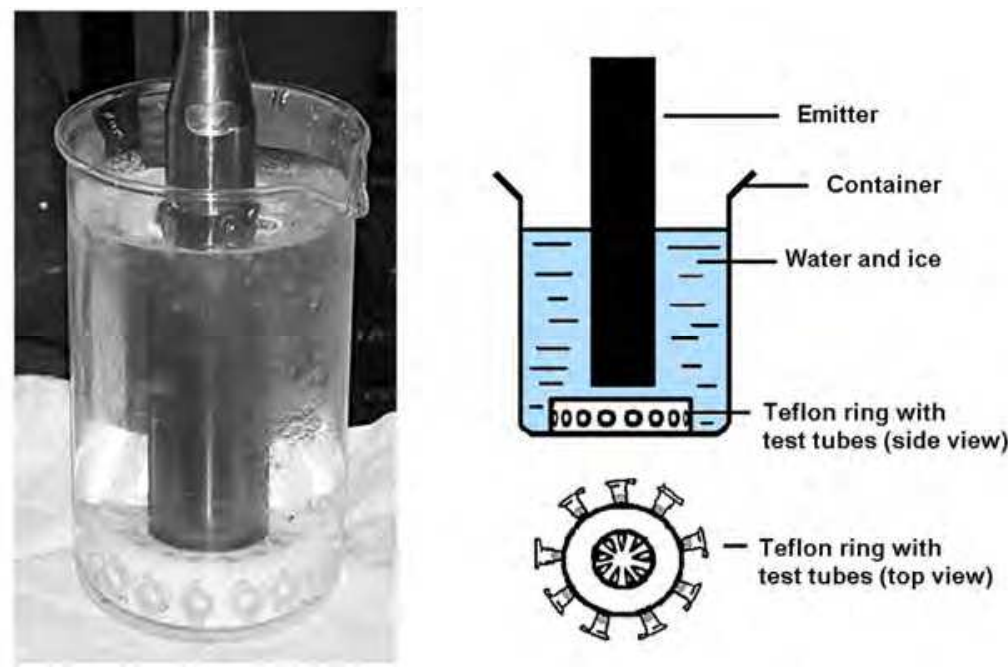

Fig. 1. The ring with test tubes and horn sonicator in a vessel with water and crushed ice. Ultrasound was generated by a $300 \mathrm{~W}$ generator UZDN-2T (Ukraine) with a frequency of 44 or $22 \mathrm{kHz}$ using the maximum power output. 


\subsection{Separation of DNA fragments in nondenaturing gel}

After sonication, the sample was combined with an equal volume of $50 \%$ glycerol with $0.02 \%$ bromphenol blue. Aliquots $(0.5 \mu \mathrm{l})$ were applied on nondenaturing polyacrylamide gel of $40 \mathrm{~cm}$ in length and $0.15 \mathrm{~mm}$ in thickness. Electrophoresis was carried out in $1 \times \mathrm{TBE}$ at $1.3 \mathrm{kV}(\sim 30 \mathrm{~W})$ for $3 \mathrm{~h}$ (gel temperature $30^{\circ} \mathrm{C}$ ) or at $300 \mathrm{~V}(\sim 2 \mathrm{~W})$ for $18 \mathrm{~h}$ at $+2^{\circ} \mathrm{C}$. Gels were dried on a glass which was pretreated with $\gamma$-methacrylpropyloxysilane and were then exposed with a luminescent screen.

\subsection{Separation of DNA fragments in denaturing gel}

To localize the DNA cleavage sites with single-nucleotide precision the sonication product was resolved by denaturing polyacrylamide gel. After sonication, the samples were combined with $180 \mu \mathrm{L}$ of a solution containing $0.15 \mathrm{M} \mathrm{NaCl}, 50 \mathrm{mM}$ Tris- $\mathrm{HCl}$ (pH 7.5), and $10 \mathrm{mM}$ EDTA. The samples were then extracted with phenol. The DNA was precipitated with ethanol, washed with $70 \%$ ethanol, dried, and dissolved in $1 \mu \mathrm{L}$ of $95 \%$ formamide (which contained $15 \mathrm{mM}$ EDTA ( $\mathrm{pH} 8.0$ ), 0.05\% bromphenol blue, and $0.05 \%$ xylencyanol FF). It was then heated for $1 \mathrm{~min}$ at $90^{\circ} \mathrm{C}$, rapidly cooled down to $0{ }^{\circ} \mathrm{C}$, and applied on polyacrylamide gel containing $8 \mathrm{M}$ urea (length: $40 \mathrm{~cm}$; gradient width: $0.15-0.45 \mathrm{~mm}$ ) (Kraev, 1988). Electrophoresis was carried out for $55 \mathrm{~min}(100 \mathrm{~W}, 2500 \mathrm{~V})$ at $60-70^{\circ} \mathrm{C}$. Afterward, the gel was fixed in $10 \%$ acetic acid and dried on a glass plate pretreated with $\gamma$ methacrylpropyloxysilane. The dried gel was exposed to a luminescent screen and then scanned with a Cyclone Storage Phosphor System device (Packard BioScience). Cleavage pattern bands were assigned to particular nucleotide sequences of fragments by comparison with the lanes of "A+G" track DNA samples.

\subsection{Impact of DNA fragment size, ultrasound frequency, $\mathrm{pH}$ and ionic strength on ultrasonic cleavage patterns}

Cleavage profiles of the 470-bp DNA fragment were obtained by nondenaturing gel (Fig. 2). The fragment contained AT clusters alternating with GC clusters. Gel was carried out at $2{ }^{\circ} \mathrm{C}$ (Fig. 2a). A similar pattern was observed when gel was carried out at $30^{\circ} \mathrm{C}$ (Fig. 2b). This temperature makes it possible to detect double-strand breaks with cleavage sites located several nucleotides apart on the two DNA strands: such sticky ends melt during PAGE under these conditions.

Figure 3 shows the cleavage patterns of the 475- and 439-bp fragments obtained by denaturing gel. The fragments carried the label on different strands of the same sequence: one 3' end of each fragment was labeled. Gel reports cleavage for only one strand under such conditions. Several sites were revealed whose cleavage rate was considerably higher than the background level.

Preliminary analysis of the nucleotide sequence of these and other fragments demonstrated that DNA strands break more readily between cytosine and guanine in the 5'-CpG-3' sequence. As Fig. 2 shows, the fragment was cleaved preferentially at several sites, which corresponded to alternating GC pairs. Many double-strand breaks arose as early as within the first four minutes of sonication. Further sonication enhanced the cleavage pattern, but the ends of the fragment still remained noncleaved. 


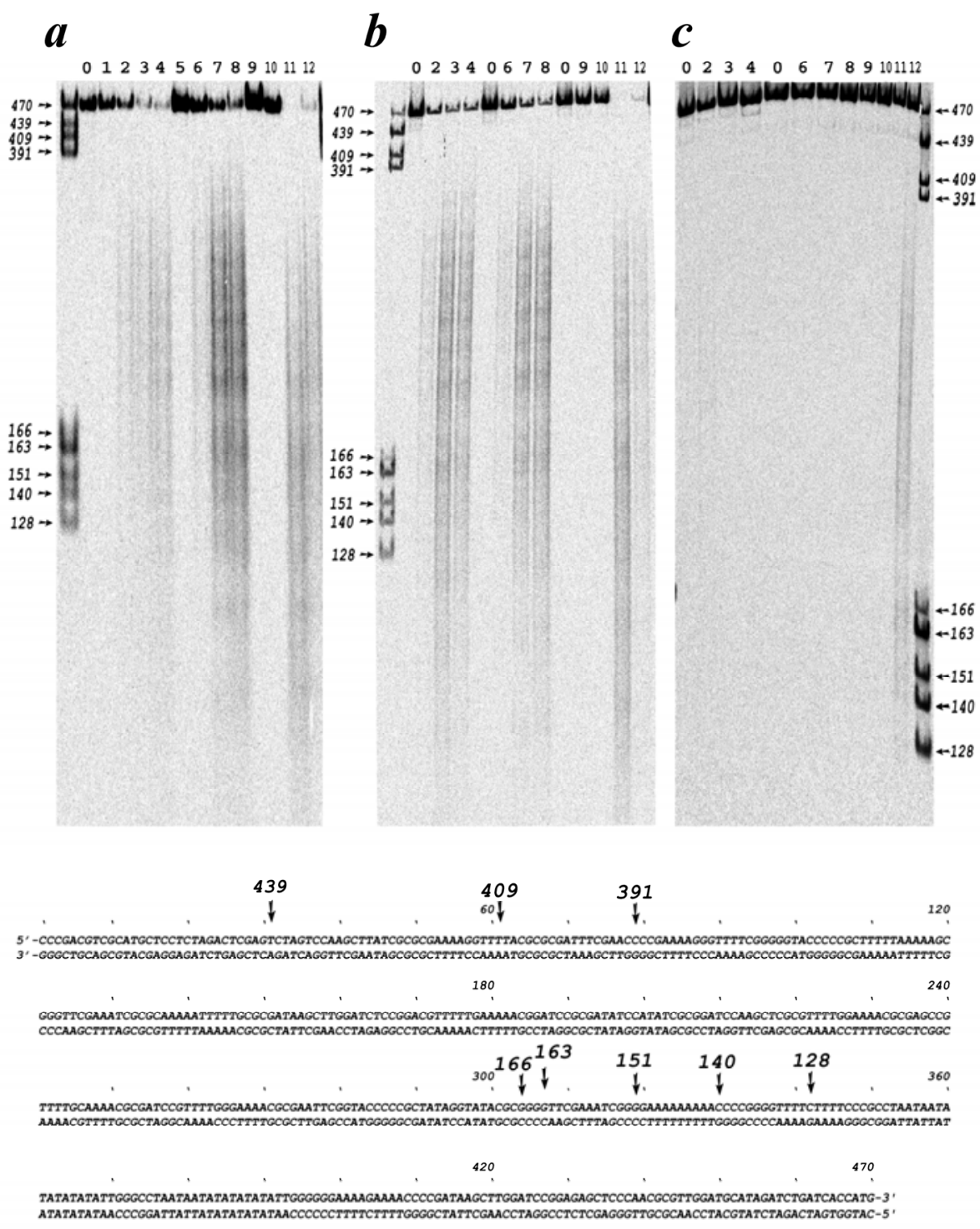

Fig. 2. Cleavage profiles of the $470-b p$ DNA fragment in nondenaturing $5 \%$ polyacrylamide gel after sonication at $44 \mathrm{kHz}$. DNA was (a) sonicated at $0^{\circ} \mathrm{C}$ and resolved at $2^{\circ} \mathrm{C}$, (b) sonicated at $0^{\circ} \mathrm{C}$ and resolved at $30^{\circ} \mathrm{C}$, or (c) sonicated at $30^{\circ} \mathrm{C}$ and resolved at $30^{\circ} \mathrm{C}$. The fragment sequence is shown at the bottom. Positions of labeled marker double-stranded DNA fragments of known sizes are shown with arrows on the electrophoretic patterns and on the sequence. The fragment was analyzed (lane 0 ) before and after sonication (lanes 1-4) in $5 \mathrm{mM} \mathrm{NaOAc}$ ( $\mathrm{pH} 7.0$ ) for 2, 4, 8, and $16 \mathrm{~min}$, respectively; (lanes 5-8) in $0.5 \mathrm{M} \mathrm{NaOAc}$ ( $\mathrm{pH} 7.0$ ) for 2, 4, 8, and $16 \mathrm{~min}$, respectively; (lanes 9,10), in $0.5 \mathrm{M} \mathrm{NaOAc}(\mathrm{pH} \mathrm{11.0)}$ for 4 and $8 \mathrm{~min}$, respectively; and (lanes 11,12) in $0.5 \mathrm{M} \mathrm{NaOAc}(\mathrm{pH} 5.0$ ) for 4 and $8 \mathrm{~min}$, respectively. 
The efficiency of cleavage slightly increased with ionic strength increasing from $5 \mathrm{mM}$ to 0.5 $\mathrm{M}$ at $\mathrm{pH}$ 7.0. When $\mathrm{pH}$ was varied, cleavage was almost undetectable at $\mathrm{pH} 11.0$, while its efficiency considerably increased at $\mathrm{pH}$ 5.0. This finding is explained by the fact that the double helix is partly unwound at alkaline $\mathrm{pH}$, which increases the flexibility and the condensation of DNA. When sonication temperature was increased to $30^{\circ} \mathrm{C}$, cleavage was almost completely suppressed (Fig. 2c). The fragment was cleaved to a significant extent at $30^{\circ} \mathrm{C}$ only at low $\mathrm{pH}$. These findings suggest that the main contribution to cleavage DNA strands is made by hydrodynamic forces which arise when cavitation bubbles collapse and which depend on the water vapor pressure, decreasing with a decrease in temperature (Suslick \& Price, 1999). The chemical processes generating radicals during cavitation play only a minor role, if any. The character of fragment cleavage was the same upon sonication at 22 and at $44 \mathrm{kHz}$.

\subsection{Elucidation of the terminal groups resulting from DNA cleavage}

Chemical cleavage of DNA with formic acid - diphenylamine reagent eliminates a purine from the cleavage site (Tate \& Petersen 1975; Belikov \& Wieslander, 1995). Thus, the bands seen in lanes " $\mathrm{A}+\mathrm{G}$ " (on figs. 3 - lanes 1; fig. 4 - lanes 1 and 18; on fig. 7 - lanes 1 and on fig. 8 - lane 10) correspond to oligonucleotides lacking the terminal purine. 3'-endlabeled fragments contain the uncharged 3'-OH group at the 3 ' end and the phosphate group, which carries two negative charges, at the 5 ' end. When the 5'-terminal phosphate is removed with calf intestinal alkaline phosphatase, the electrophoretic mobility of DNA fragments changes (Fig. 3; lanes 1,2). The mobility of a fragment depends on its molecular weight, its total charge, and the gel density. The longer the fragment, the lower the contribution of the two terminal charges to the total charge and the weaker the dependence of the electrophoretic mobility on the fragment size.

For example, the 20 base pairs (b.p.) fragment without phosphate at the $5^{\prime}$ has overall negative charge of $19 \mathrm{e}$, while the terminal phosphate adds $2 \mathrm{e}$ which results in $21 \mathrm{e}$ for total charge in presence of $5^{\prime}$ phosphate. Thus, the relative electric charge difference for 20 b.p. fragments is $11 \%$. The corresponding values for 40 b.p. and 90 b.p. fragments would be 41 : $39-5 \%$ and $91: 89-2 \%$, respectively. The length of the fragment is less affected with the presence of 5' phosphate. Experiment demonstrates that in denaturing $6 \%$ gel electrophoretic mobility shifts by about 1.5 steps in the region of 20-mer oligonucleotides, by 1 step in the region of 40-mer oligonucleotides, and by 0.5 steps in the region of 90 -mer oligonucleotides. In 14\% gel, similar shifts are observed in the regions of 14-, 25-, and 55-mer oligonucleotides, respectively. The bands observed after sonication of the DNA fragment exactly coincided with the bands observed after its chemical cleavage at purines (Fig. 3 and Fig.4). This result indicated that the products had phosphates at their 5 ' ends.

\subsection{Evidence of mechanochemical nature of observed cleavage}

Fig. 4 demonstrates the gel image obtained after sonication of the DNA fragments for various periods of time. This image represents the results of ultrasonic irradiation of three fragments that differed in initial length (311, 251, and 218 base pairs, respectively) but shared the same base pair sequences. The left part of the gel contains lanes that correspond to cleavage of the longest fragment (lanes 1-6). The central part represents lanes corresponding to cleavage of the middle-sized fragment (lanes 7-12), and the lanes at the right side of the gel demonstrate the cleavage patterns of the shortest fragment (lanes 13-17). 


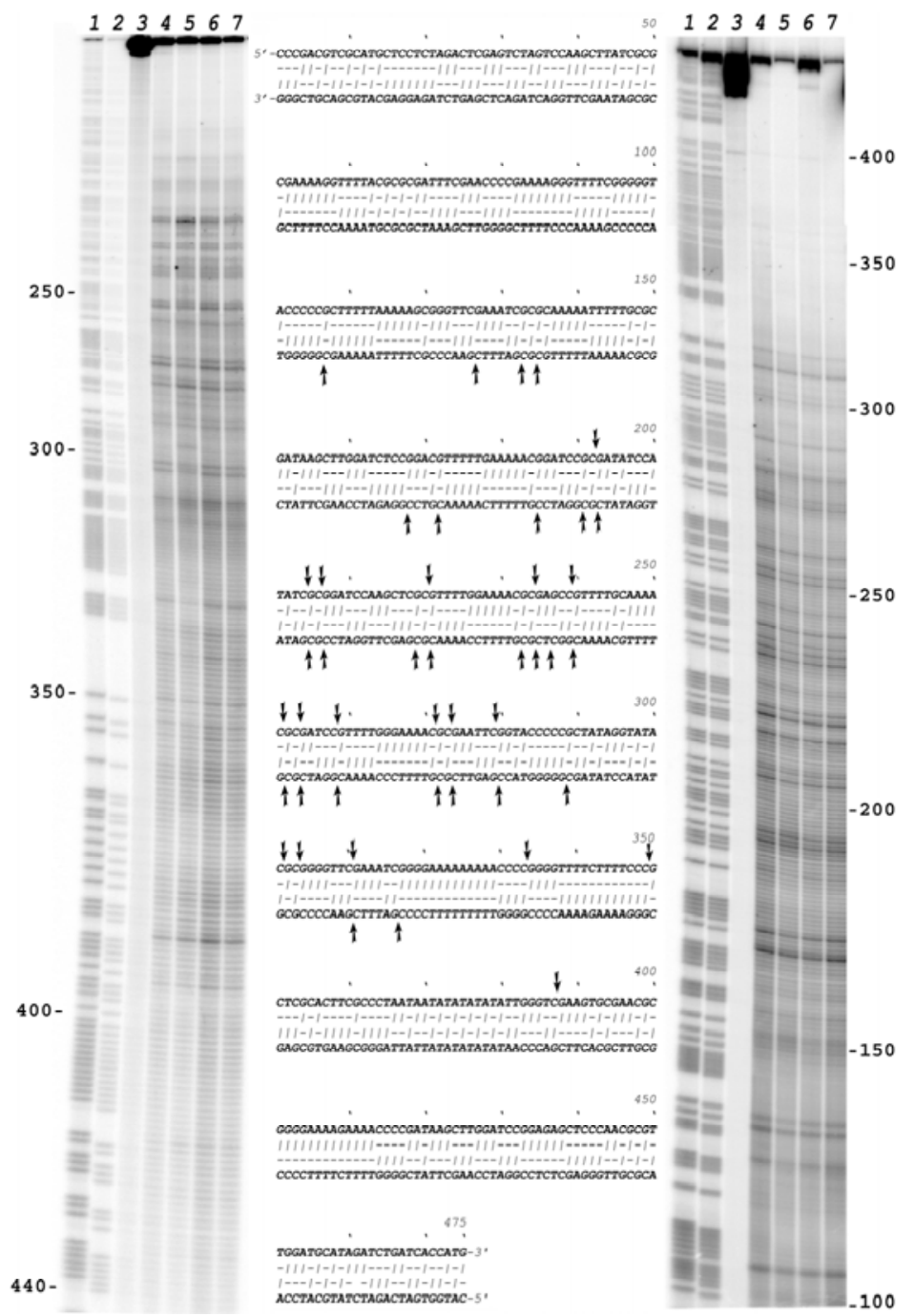

Fig. 3. Cleavage profiles of DNA fragments in denaturing $6 \%$ gel after sonication at $44 \mathrm{kHz}$ for $20 \mathrm{~min}$. Lane 1, products of chemical cleavage at purines with subsequent treatment with calf intestinal alkaline phosphatase; lane 2, product of chemical cleavage at purines by formic acid - diphenylamine reagent.; lane 3, the initial fragment without treatment; lane 4, the fragment sonicated in isolation; and lanes $5-7$, the fragment sonicated in the presence of $1,0.5$, or $0.25 \mu \mathrm{M}$ of Pt-bis-netropsin, respectively (for details see section 6.2.). The nucleotide sequence of the fragments is shown in the center. To simplify comparison with the bands seen on gel, purines are marked with slants for each strand. The sites with a cleavage rate far higher than the cleavage intensity baseline are indicated with arrows. The cleavage profiles shown on the left correspond to the cleavage of the upper strand, i.e. when this strand is radiolabeled, while the cleavage patterns on the right side represent the cleavage of the lower strand. 


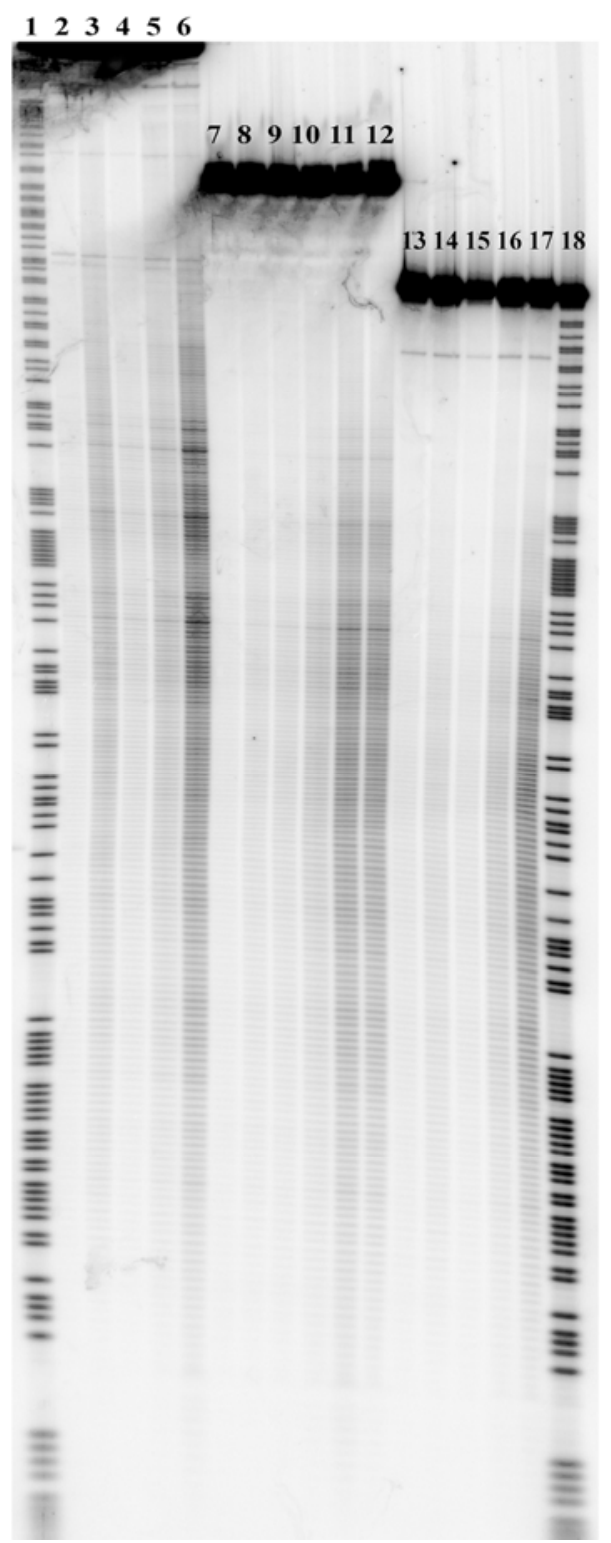

Fig. 4. Cleavage pattern of DNA fragments in 6\% denaturing gel after irradiation with ultrasound $(22 \mathrm{kHz})$. Lanes 1 and 18: Chemical cleavage at purines by formic acid diphenylamine reagent. Lanes 2, 7, and 13: Sonication of fragments for $2 \mathrm{~min}$. Lanes 3, 8, and 14: Sonication of fragments for $2 \mathrm{~min}$ in the presence of $50 \%$ glycerol. Lanes 4, 9, and 15: Sonication of fragments for $4 \mathrm{~min}$. Lanes 5, 10, and 16: Sonication of fragments for $8 \mathrm{~min}$. Lanes 6, 11, and 17: Sonication of fragments for $16 \mathrm{~min}$. Lane 12: Sonication of fragments for $16 \mathrm{~min}$ in the presence of $0.5 \mathrm{M}$ tiourea. 
It is clear that increasing the irradiation time from 2 to 16 min leads to a sufficient increase in overall cleavage intensity for all three types of fragments. Fig. 4 also demonstrates that the addition of tiourea has no visible effect on the cleavage patterns (lanes 11 and 12). The same result was obtained when others free radical scavengers (dithiothreitol and sodium ascorbate) were added to the irradiated solution (data not shown). On the other hand, adding $50 \%$ glycerol, which increased the viscosity of the solution by roughly 10 -fold, led to a significant increase in cleavage intensities (lanes 3, 8, and 14). The cleavage patterns obtained by adding glycerol are similar to those obtained without it but with a longer irradiation time. Thus, increasing the viscosity of the solution leads to an overall increase in cleavage intensity but does not affect the relative intensities of cleavage. This dependence of the ultrasonic cleavage intensity on the solution viscosity is one of the distinctive features of a mechanochemical reaction (Basedow \& Ebert, 1977).

Fig. 3 and 4 also demonstrates the positional effect (i.e., the damping of ultrasonic cleavage) at sites that are closer to the ends of the DNA fragments. Accordingly, the darkest bands of the cleavage patterns that give the highest values of cleavage intensity correspond to breakages at the central part of the DNA fragments. This relevant feature of ultrasonic cleavage patterns of DNA also supports the idea of mechanochemical nature of the cleavage process observed in our experiments. The significant role of the positional effect and the minor influence of free radical scavengers on the observed cleavage patterns lead us to conclude that the cleavage of DNA induced by free radicals in solution was negligible in our experiments. The distinctive features of free radical cleavage of DNA on the gel (i.e., the emergence of overall cleavage background with no positional preference) were observed only at higher temperature conditions $\left(>25^{\circ} \mathrm{C}\right.$; data not shown).

\subsection{What physical processes in aqueous solution under sonication lead to DNA cleavage?}

The ultrasonic cleavage of DNA reported here is most likely the result of hydrodynamic shearing stresses caused by the collapse of cavitation bubbles (Basedow \& Ebert, 1977, Suslick \& Price, 1999). Their collapse results in a drastic increase of local temperature and pressure (Margulis, 1984; Didenko, et al., McNamara et al., 1999). The critical size of the bubbles weakly depends on the sound frequency in a wide frequency range. Shearing forces that act on the DNA fragments are thought to originate from high-velocity gradients of water near the collapsing bubble. It is known that in the case of asymmetric collapse, the velocity of the microjets exceeds $100 \mathrm{~m} / \mathrm{s}$ (Suslick \& Price, 1999), whereas the theoretical value of the bubble's interface velocity in the case of symmetrical collapse might exceed 200 $\mathrm{m} / \mathrm{s}$. High-velocity gradients in the streaming solution may cause mechanical deformation of the molecule by friction forces. Thus, the observed cleavage of DNA fragments most likely represents a complex mechanochemical process, which includes mechanical deformation of the molecule before the actual chemical reaction takes place (Basedow \& Ebert, 1977). Because cavitational flows are accompanied by turbulence, any mathematical treatment of the problem is restricted to highly simplified models.

To estimate the values of the shearing forces that act on DNA molecules in cavitating solution, we used the model proposed by Thomas (Thomas, 1959). This model is generally accepted for describing the degradation of polymers in cavitating solution. Our computation of cavitation bubble dynamics showed that in the final stage of the bubble's collapse, the 


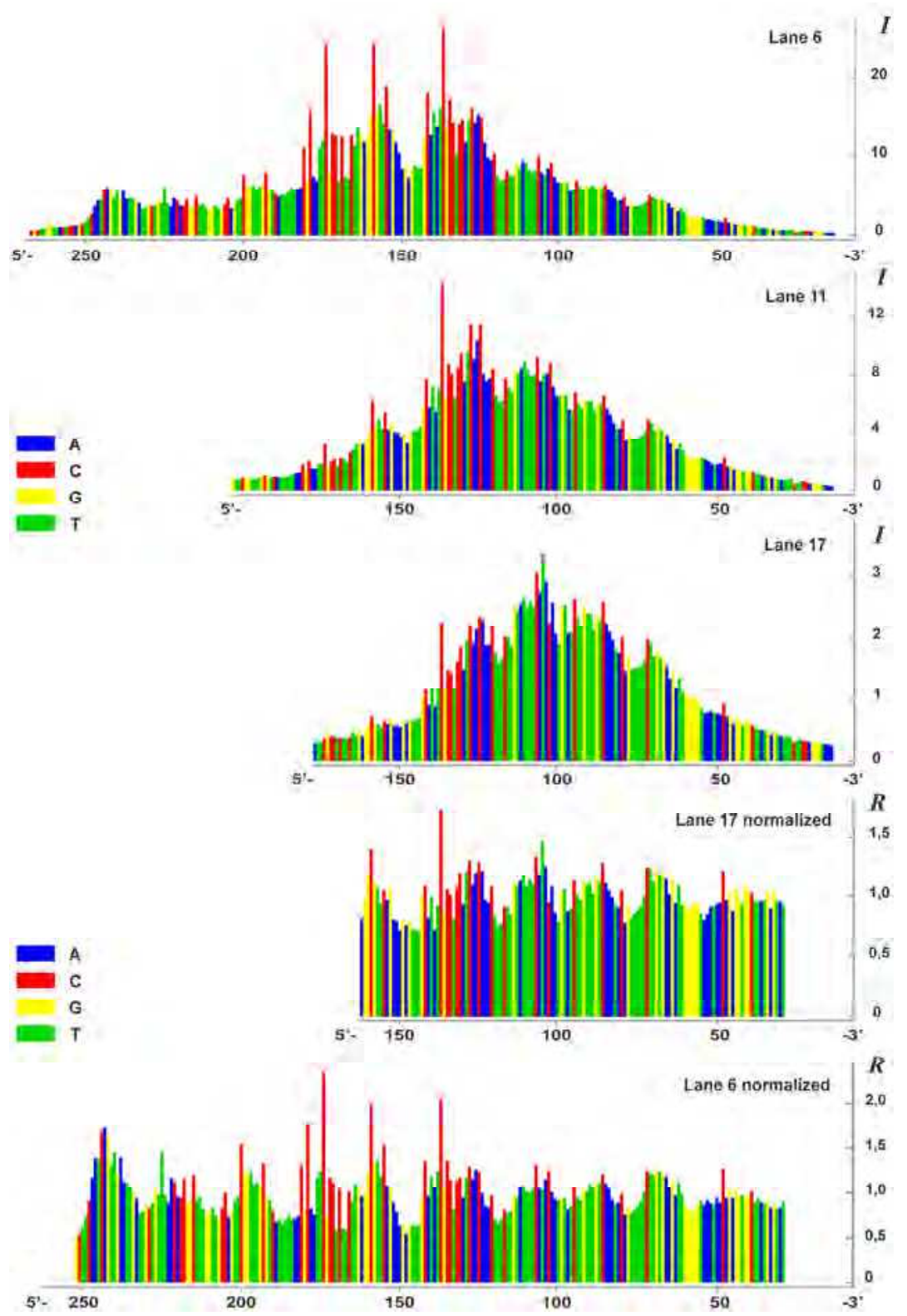

Fig. 5. Cleavage pattern of lanes obtained by computer digitization of the gel band densities. Histograms correspond to lanes in Fig. 4. The upper plot represents the profile of intensity of cleavage (I) for lane 6 and is followed by the same type of profiles built for lanes 11 and 17. The last two plots represent profiles of the relative intensity of cleavage (R) for lanes 17 and 6 , obtained by the moving-average method, to demonstrate the normalization procedure. 
radial velocity gradient calculated for water flow near the bubble's interface exceeded $10^{7} \mathrm{~s}^{-1}$. Calculations showed that such flow gradients are capable of producing stretching forces acting on a 200 base pair DNA fragment of $>3 \mathrm{nN}$ (unpublished results). Single-molecule studies of various polymers have shown that the rupture force of a single covalent bond is in the nanonewton range and depends logarithmically on the stretching rate (Bustamante, 2000).

We should note that single-molecule studies on double-stranded DNA mechanics have clearly demonstrated the existence of several stages upon DNA stretching, such as B/S-form transition and melting (Bustamante et al., 2000). Nevertheless, the timescale of these experiments is approximately seconds, whereas the impulsive stretching force in cavitation flow acts on timescales of several nanoseconds. Hence, we assume that drastic conformational changes in DNA, such as the B/S transition, do not occur in this case.

\subsection{Results of the gel digitization}

Fig. 5 presents the results of the gel digitization. Profiles of the intensity of cleavage (I) for several lanes of Fig. 4 are shown. Profiles of the relative intensity of cleavage (R) calculated for 2 lanes by normalization procedure (which eliminates the positional effect) are given below the intensity profiles. The values of the relative intensities of cleavage along with the corresponding local nucleotide sequences are used as the input data for a statistical analysis of sequence effects on ultrasonic cleavage of DNA.

We analyzed the cleavage patterns for 48 different radiolabeled DNA restriction fragments with lengths ranging from 100 to several thousand base pairs from $\lambda$-phage DNA and plasmids pBR322, pUC18, and pGEM7(f+) (Promega), and their modified analogs, which contained different insertions of various eukaryotic functional genomic sequences (like promoters) into the polylinkers. For statistical analysis, we used the central parts of the gels where the bands were clearly separated. Because experiments with the same sequences showed some data scattering, these experiments were repeated two or three times. It should be noted that $1-2 \%$ of the greatest intensities, as well as $1-2 \%$ of the lowest intensities, were out of scope in the statistical treatment. The first group of excluded values (i.e., the greatest intensities) came from gel defects (an example of such a defect is clearly seen in the lowerleft corner of Fig. 3) or foreign fragments, whereas the second group (the lowest intensities) results from incorrect approximation of the overall band intensity value due to its curvature or overlap with neighboring band (such overlaps can also be seen in the upper part of the lanes shown in Fig. 3 and Fig.4). The nucleotide sequences and other supplementary materials are available at http://grok.imb.ac.ru/en/.

\section{Gel data analysis}

The first stage of gels analysis comprises computation of band intensities and their correlation with corresponding nucleotide sequence. The gel surface generally contains defects, strongly hindering data digitization and further processing. The nonhomogeneous thickness, air bubbles, and different amounts of salts in the deposited samples lead to the bending and deformation of the tracks and shift the bands on different tracks relative to one another. The labeled DNA fragment solution often has small contaminations of foreign fragments. Due to imperfect wells or well loading different lanes often have different total intensity of bands. Prolonged physical or chemical treatment of labeled fragments leads to 
the "double strike" effect, increasing the fraction of short labeled fragments in the reaction mixture. The mechanochemical origin of DNA cleavage leads to the damping of ultrasonic cleavage near the ends of the fragments. All these factors point to the difficulty of quantitative analysis of cleavage data for DNA with a definite nucleotide sequence. Therefore, it is important to seek adequate methods for analyzing the experimental data.

For primary PAGE data analysis we used the SAFA package (Das, 2005). This software was exploited to align the gel lanes, calculate the overall intensity of each band and correlate the band sequence with the corresponding nucleotide sequence. The calculation of overall band intensities produced by SAFA is based on several models (Shadle et al, 1997; Takamoto, et al., 2004) introduced earlier to account for such effects as band overlapping and asymmetric distribution of single band intensity along the gel which is better fit with Lorentz function rather than the Gaussian function.

As far as band intensities are sensitive to various parameters of the experiment, it is important to calculate the normalized values of cleavage intensities. The strategy of normalization procedure depends on the observed properties of cleavage patterns: in the case of purely chemical cleavage - such as $\mathrm{OH}$ radical-induced cleavage - the positional preference of breakage along the molecule is attributed only to local sequence effects on DNA structure. In this case no general trends in cleavage patterns are observed provided that the cleavage is not efficient enough to produce "double strike" effect. In order to perform normalization of such cleavage pattern it is sufficient to validate the baseline of cleavage intensity which might be calculated by averaging the intensity values for a number of particular bands. In case of $\mathrm{OH}-$ radical induced DNA cleavage analysis the baseline might be determined by averaging the cleavage intensity of the common sequences which flank the test DNA sequence (Greenbaum et al, 2007). Despite the success of this normalization method in the case of OH-radical induced cleavage, it is not suitable for the treatment of cleavage patterns possessing general trends of cleavage variation along the fragment.

Ultrasonic cleavage patterns demonstrate pronounced positional effect, i.e. the dependence of the band intensity value on its position in the gel. In order to analyze the sequencedependence of cleavage it is important to eliminate this general trend and operate with normalized values of cleavage intensities. This procedure might be performed using several approaches.

We have compared the efficiency of several methods listed below: a) no trend elimination and normalization of band intensity by dividing band intensity by the mean value of bands intensities calculated using all analyzed bands of the lane; b) using the moving average method with various window sizes; c) describing the positional effect in terms of asymmetric gauss functions; d) approximation of the trend with various degree polynomials (Nechipurenko et al, 2009).

As far as the basic goal of these approaches is retrieving the values of relative cleavage intensities for each band, the efficiency of each method might be characterized after calculation the mean value of cleavage for all bands which were analyzed. In the case of large sample size, comprising many gels and many various sequences, this value should be close to 1 . Thus, the calculated mean value might be used to compare the methods listed above.

The comparison of these approaches performed during the analysis of DNA ultrasonic cleavage has shown that the best results are obtained with the moving average method. 
Further we will focus on this method which shows good performance in case of low-term specificity observed for ultrasonic cleavage, hydroxyl radical cleavage, $\mathrm{X}$-ray and laserinduced breakages of DNA. The intensities of cleavage in these experiments do not demonstrate such great variations which might be seen for DNAse I-induced cleavage, when the cleavage in particular sites is hundreds and even thousands times greater than in the other sites of DNA.

The absolute value of an individual band's intensity, or cleavage intensity, is further denoted as $I$, while the normalized value, i.e. the relative intensity of cleavage, is denoted as $R$. We normalized the band intensities by dividing their values by the local basic band intensity values, which were determined by using the moving-average method separately for each band. Thus, the array of $R_{n}$ values was calculated using the formula:

$$
R_{n}=(2 m+1) \frac{I_{n}}{\sum_{k=n-m}^{n+m} I_{k}}
$$

where $R_{n}$ denotes cleavage rate corresponding to band number $n$, and $I_{k}$ denotes the intensity of band number $k$, while $(2 m+1)$ is the window size which is constant during analysis.

The optimal number of adjacent bands used for the mean intensity calculation has been shown to be 31. Lowering this number results in an increased scattering of data points, whereas increasing the number of adjacent bands does not change the ratio of the obtained relative intensities of cleavage but does lead to a decrease in the number of analyzed data points.

\section{Statistical analysis of the sequence-dependent DNA ultrasonic cleavage}

To study the relationship between the nucleotide sequence and the relative intensity of ultrasonic cleavage $(R)$ of the central phosphodiester bond in all possible di- and tetranucleotides, we used analysis of variance, nonparametric methods (i.e., the KruskalWallis test and Brown-Mood test) and multiple-comparison methods (i.e., Tukey-Kramer test, and Dunn test) (Zar, 1999). We found that the nonparametric analysis yielded the same results as the parametric analysis.

The results of the statistical analysis of the 20,588 relative cleavage intensities for each of 16 dinucleotides are shown in Table 1 and on fig. 6 . The sample mean values of the relative cleavage intensities (cleavage rates, $\bar{R}$ ), of the dinucleotides were found not to be significantly different from the corresponding values from our previous study (Grokhovsky et al., 2008) where the total length of the analyzed sequences was $\sim 2500$ nucleotides. The effect of the dinucleotide type on the cleavage rate was also shown to be statistically significant ( $\mathrm{p}<<0.05)$. ). The statistical results for relative intensities of ultrasonic cleavage (R) of the central phosphodiester bond in all 256 tetranucleotides are available at http://grok.imb.ac.ru/en/

In addition we found a significant difference between the cleavage rates at complementary dinucleotides. Therefore, cleavage of particular phosphodiester bond does not always result in cleavage of the opposite phosphodiester bond in the complementary strand. Importantly, we showed that the cleavage rates at dinucleotides $d(C p C), d(C p T), d(C p A)$, and $d(C p G)$ are 


\begin{tabular}{|c|c|c|c|c|c|c|}
\hline \multirow{2}{*}{$\begin{array}{c}\text { Type of } \\
\text { di-nucleotide }\end{array}$} & $N$ & $\bar{R}$ & $S$ & \multirow{2}{*}{$S_{\bar{R}}$} & \multicolumn{2}{|c|}{ The 95\% confidence limits } \\
\cline { 6 - 7 } & & & & & Lower limit & Upper limit \\
\hline AA & 1636 & 0.919 & 0.129 & 0.003 & 0.913 & 0.926 \\
\hline AC & 1076 & 0.913 & 0.128 & 0.004 & 0.905 & 0.920 \\
\hline AG & 1028 & 0.900 & 0.124 & 0.004 & 0.892 & 0.907 \\
\hline AT & 1374 & 0.904 & 0.119 & 0.003 & 0.898 & 0.910 \\
\hline CA & 1265 & 1.160 & 0.209 & 0.006 & 1.149 & 1.172 \\
\hline CC & 1141 & 1.007 & 0.144 & 0.004 & 0.999 & 1.015 \\
\hline CG & 1230 & 1.444 & 0.334 & 0.010 & 1.426 & 1.463 \\
\hline CT & 1077 & 1.130 & 0.198 & 0.006 & 1.118 & 1.142 \\
\hline GA & 1153 & 0.970 & 0.133 & 0.004 & 0.962 & 0.978 \\
\hline GC & 1317 & 0.954 & 0.146 & 0.004 & 0.947 & 0.962 \\
\hline GG & 1168 & 0.922 & 0.145 & 0.004 & 0.914 & 0.931 \\
\hline GT & 1101 & 0.952 & 0.126 & 0.004 & 0.944 & 0.959 \\
\hline TA & 1065 & 0.973 & 0.120 & 0.004 & 0.966 & 0.980 \\
\hline TC & 1173 & 0.912 & 0.131 & 0.004 & 0.904 & 0.919 \\
\hline TG & 1305 & 0.979 & 0.126 & 0.003 & 0.972 & 0.986 \\
\hline TT & 1672 & 0.932 & 0.127 & 0.003 & 0.926 & 0.938 \\
\hline
\end{tabular}

Table 1. Designations: $N$ - the sample size; $\bar{R}$ - the sample mean; $S$ - standard deviation; $S_{\bar{R}}$ - standard error of mean.

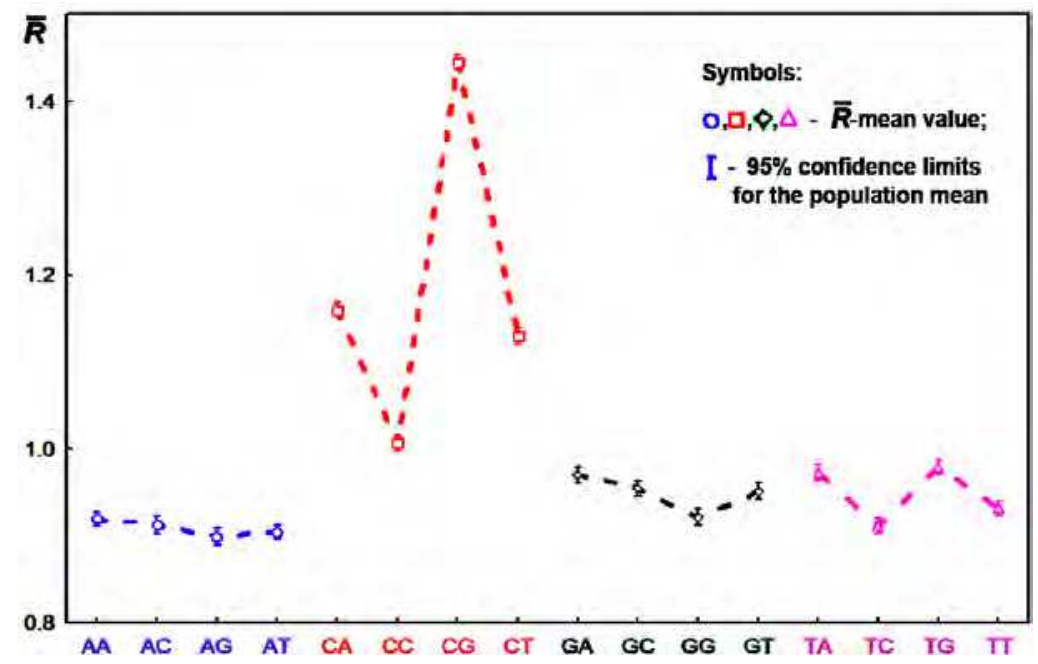

Fig. 6. The sample mean values of the relative intensity of cleavage for all dinucleotides, and $95 \%$ confidence limits for the population mean. 
significantly different from each other and all much higher than from the cleavage rates obtained for all other dinucleotides. The cleavage rate of dinucleotide $d(C p G)$ was the highest among all 16 dinucleotides.

As a result of our analysis we showed the significant dependence of nucleotide type on the ultrasonic cleavage rate at the 3 '-position in all four groups of dinucleotides $(\mathrm{p}<<0.05)$. Moreover, the results of the statistical analysis of the relative cleavage intensities of the central phosphodiester bond in tetranucleotides showed the context dependence of cleavage rates in dinucleotides.

To estimate the contribution of the different analyzed DNA restriction fragments to the overall variability of ultrasonic cleavage rate we used two-level nested ANOVA. This study was performed for precisely resolved runs of bands in the cleavage patterns corresponding to cleavage of 140 DNA restriction fragments of known base pair sequences. The size of such runs varied from 100 to 250 base pairs. Two following factors were tested affecting the values of ultrasonic cleavage rate: the type of dinucleotide (the constant factor) and the type of fragment including the analyzed phosphodiester bond cleavage in the full length sequence of this fragment (the random factor).

The results of statistical analysis have led to the conclusion that the influence of both factors is statistically significant for dinucleotides of types $\mathrm{CN}, \mathrm{GN}, \mathrm{TN}$ (where N=A, C, G, T ). Contribution of the random factor (DNA fragment) to the overall variability of cleavage rates is much smaller than the contribution of the constant factor, i.e. of the type of dinucleotide. For dinucleotides of type AN (N=A, C, G, T ) only the random factor's influence was shown to be statistically significant.

Thus, sequence effects on conformational dynamics in any dinucleotide seem to propagate beyond mono and dinucleotide levels: further neighboring nucleotides might also influence the dynamics of sugar phosphate backbone.

\section{Ultrasonic cleavage of nicked DNA}

Fig. 7 demonstrates the PAGE data obtained after ultrasonic irradiation of intact and nicked fragments of DNA. The initial length of fragments was 253 base pairs. Band numeration is given from $5^{\prime}$ - to the $3^{\prime}$-end of the labeled strand. The positions of the nicks in complementary strand are given at the right side of the lane.

The results of analysis performed for over 20 cleavage patterns of nicked DNA made it possible to conclude that the intensity of ultrasonic cleavage near the nick is one order of magnitude higher than intensity of ultrasonic cleavage in the same sites of the intact dsDNA fragments.

If one chain of dsDNA is nicked the intensity of cleavage near the nicks is (in average) about 20 times higher than cleavage in the same sites of the intact dsDNA fragments (Fig. 7 a,b ) (Il'icheva I. A. et al, 2009). At the same time, the cleavage rates in positions beyond the regions of the nick markedly grow weak even comparing to the sequence-specific cleavage of intact double-stranded DNA fragments (Fig. 7 c). Thus, the presence of the nick serves as an expressive structural indignation, which exceeds modulation of the structure caused by the base-pair sequence and is capable of absorbing mechanical stresses applied to the nearby sites of the molecule. 


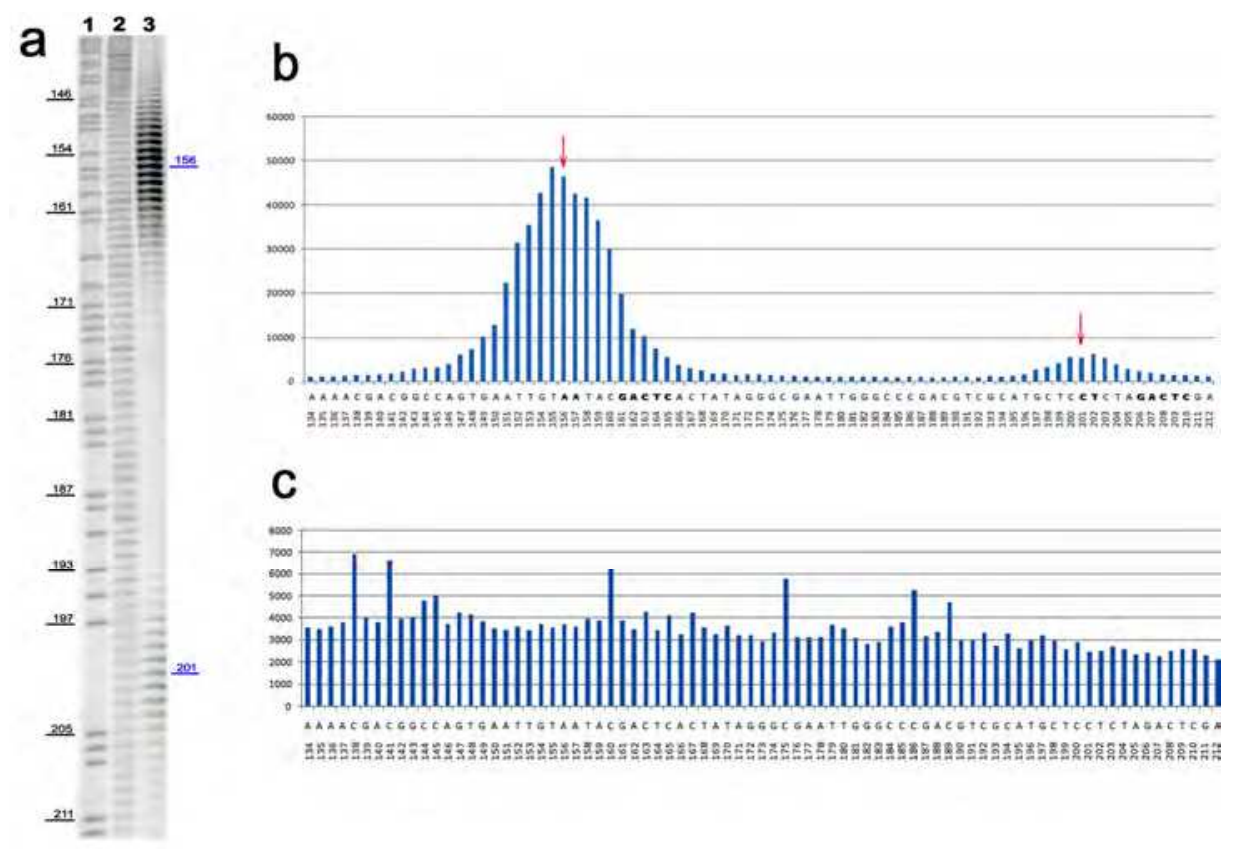

Fig. 7. Ultrasonic cleavage patterns of intact and nicked dsDNA a- Cleavage pattern of dsDNA: lane 1 corresponds to chemical cleavage of the dsDNA fragment by the purines; second lane represents ultrasonic cleavage pattern of primarily intact dsDNA; lane 3 demonstrates cleavage pattern of twice nicked dsDNA. b- Band intensity data for third lane of the gel. The local maximums of cleavage intensities are disposed in front of the nicks. Both regions of cleavage enhancement spread about $10 \mathrm{~b}$. p. around the nick and their amplitudes depend on the nick distance from the ends of doublestranded DNA fragment. c- Cleavage profile of the second lane corresponding to ultrasonic cleavage of intact dsDNA fragments without nicks shows sequence-specific cleavage of DNA.

\section{Ultrasonic footprinting}

\subsection{Sequence-specific ligands alter the local conformation of the DNA double helix}

The structure of double-stranded DNA is not perfectly monotonous, but depends on the nucleotide sequence. The nucleotides differ in geometry, and their combinations show various deviations from the ideal helical structure: bends, turns, and changes in the widths of the minor and major grooves. Such features are of importance for DNA condensation and recognition by various proteins in the cell (Crothers, 1987; Tolstorukov et al., 2004). In addition, structural changes arise in DNA when the parameters of its aqueous environment are changed or various ligands are bound. A convenient model for studying the local parameters of the double helix is provided by low-molecular-weight sequence-specific ligands, which bind to particular DNA sequences (Gursky et al., 1983; Zimmer, Ch. \& Wahnert, 1986; Bailly et al., 2005). 


\subsection{Pt-bis-netropsin changes the DNA ultrasonic cleavage rate}

The above data suggest that sonication can be used to probe the local conformation of the DNA double helix and for localization of different ligands on DNA. Previously we have shown that X-ray irradiation of restriction fragment complexes with a platinum(II)containing ligand results in DNA cleavage at the location of the platinum atom (Grokhovsky \& Zubarev, 1991). This effect is obviously due to the preferential adsorption of X-ray quantum by the atoms with large atomic weights, with subsequent emission of Auger electrons and generation of a multicharge positive ion. Pt-bis-netropsin have been used in those experiments (Grokhovsky et al., 1992) and its binding sites were localized on the DNA fragment with a known sequence. Fig. 8 demonstrates that the sites where the sugarphosphate backbone was cleaved in both strands (long arrows) were detected in regions tightly bound with Pt-bis-netropsin and corresponded to the position of the platinum atom. Netropsin residues orient differently relative to the DNA helix and recognize two symmetrical consensus sequences, 5'-TTTT-3' (underlined). The orientation of the CO-NH groups of each residue of the netropsin within the complex coincides with the $5^{\prime}-3^{\prime}$-direction of the AAAA tetranucleotide. (Grokhovsky et al., 1992). A scheme of the complex of Pt-bisnetropsin with DNA is shown on the right. However, it remained unclear why minor cleavage sites are detectable in a sequence of alternating AT pairs.

Also we have studied the DNA binding properties of a series of bis-linked netropsin and distamycin derivatives (the chemical structure of distamycin is very similar to the netropsin) in which two monomers were bridged by different dicarboxylic acid and peptide residues (Nikolaev et al., 1996; Surovaya et al., 1996, 2008). Using circular dichroism (CD) spectroscopy and DNase I footprinting studies it was found that bis-linked netropsin derivatives bind selectively to clusters of AT- base pairs and form several types of complexes with DNA. They exhibit strong preference for binding in the extended conformation to long clusters of AT-base pairs. In the complex, each bound bis-netropsin molecule covers approximately one turn of the DNA helix in such a way that both netropsin -like fragments are implicated in specific interaction with DNA base pairs. The observed preference of Pt-bridged bis-netropsin for binding to DNA regions with the sequence 5'-TTTTAAAA-3' and lower affinity to the site in which blocks of Ts and As are interchanged can be explained by the increased width of the minor groove in the DNA site with 5'-TpA -3' step.

In 1992 using NMR techniques Fagan \& Wemmer have shown that the minor groove can accommodate not only a single distamycin molecule, but also side-by-side antiparallel binding of two distamycin molecules (Fagan \& Wemmer, 1992). Further analysis of the binding of Pt-bis-netropsin with double-stranded oligonucleotides revealed complexes of sandwich type (Surovaya et al., 2001, 2002, 2008). In this case, two netropsin residues of a Ptbis-netropsin molecule are arranged as a parallel pin which forms a tight complex with a sequence of four alternating AT pairs (Fig. 8, left scheme).

Evidently, the increased width of the minor groove is needed for simultaneous accommodation of two netropsin-like fragments and cis-diamminoPt(II) group of the bisnetropsin molecule in the minor DNA groove. The cis-diammino-Pt(II) bridged bisnetropsin and bis-netropsins containing oligomethylene linkers can also bind in the parallelstranded hairpin form to shorter DNA regions with the sequence 5'-TATAT-3' . Molecular model building studies revealed that two parallel oligopyrrole carboxamide chains can be sandwiched in the minor DNA groove and form bifurcated hydrogen bonds with AT-base pairs. Parallel-stranded hairpin motifs extend the possible repertoire of hairpin polyamides that can be used for DNA sequence recognition and drug design. A head-to-tail bis- 
netropsin in which two monomers are bridged by a triglycine residue exhibits different DNA binding properties. In close similarity with Pt-bridged bis-netropsin it binds to a long AT-cluster in the extended conformation. However, it can not form intramolecular parallel hairpin structure and binds to DNA in the form of dimer or hiher order associates stabilized by interaction between the halfs of two bis-netropsin molecules bound at adjacent AT-rich sites on DNA (Grokhovsky, et al., 1998). Different complex geometries are characterized by distinctly different $C D$ patterns and can be discriminated by CD spectroscopy. Footprinting and $\mathrm{CD}$ studies revealed that affinities and specificities shown by bis-netropsins to AT-rich regions on DNA depend on their nucleotide sequences, local DNA conformation and width of the DNA minor groove. Sonication can be used to localize the preferred positions of this netropsin derivatives on DNA.
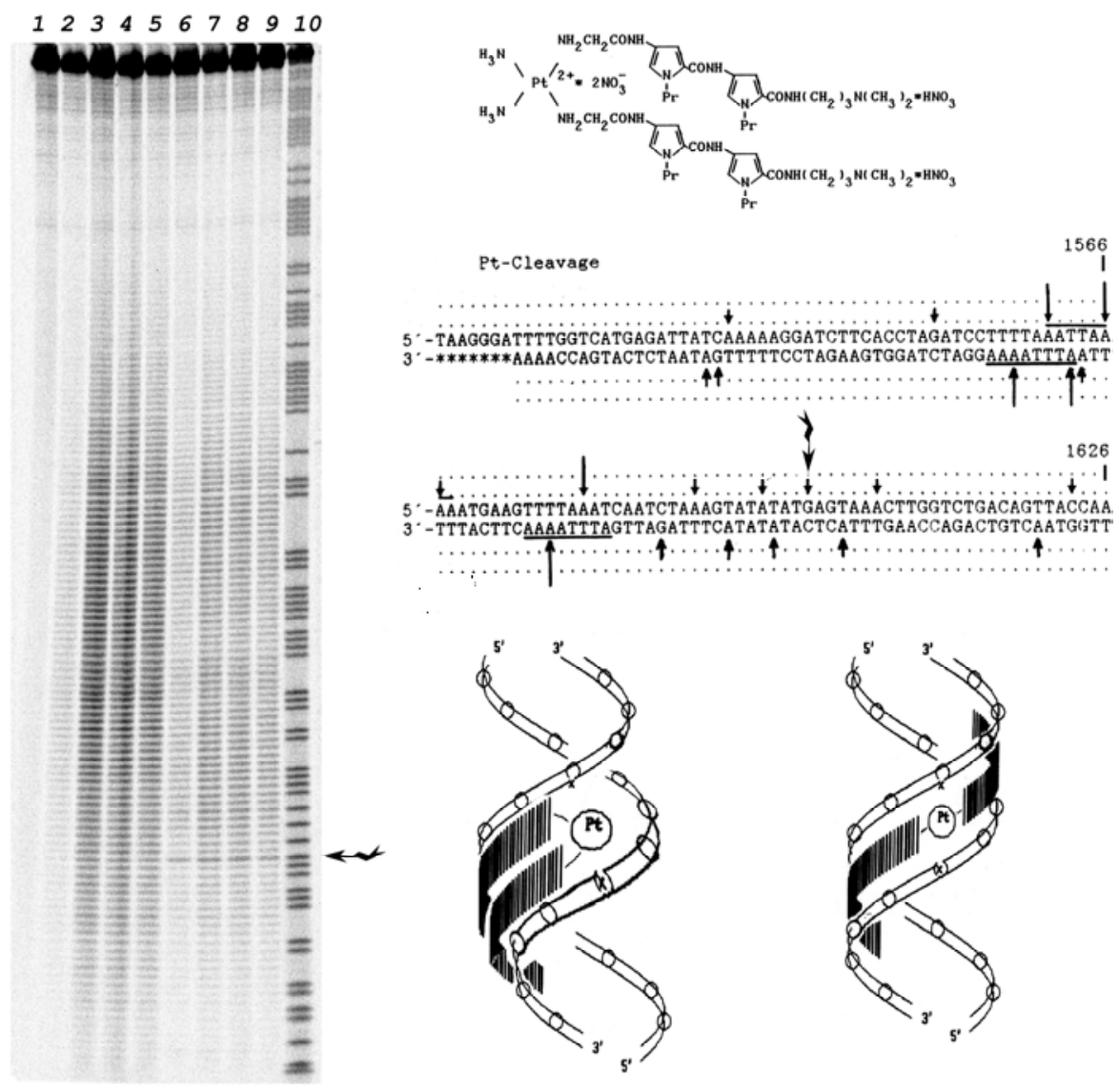

Fig. 8. Cleavage pattern of the 166-bp fragment in denaturing $6 \%$ gel after sonication at $44 \mathrm{kHz}$. The fragment was analyzed before (lane 1) and after (lanes 2-5) sonication for 2, 4, 8, and 16 min, respectively; ((lanes 6-9) - sonication in the presence of $0.5 \mu \mathrm{M}$ Pt-bis-netropsin for 2, 4, 8, and 16 min, respectively; and ((lane 10) chemical cleavage at purines. Plain arrows indicate the sites of complex cleavage upon exposure to X-rays (Grokhovsky \& Zubarev, 1991). A wavy arrow indicates the site where sonication-induced cleavage became more intense. 
When a complex of Pt-bis-netropsin with DNA fragment was sonicated (Fig. 8), the average background cleavage was slightly decreased in sites where the ligand was bound to DNA in the extended conformation (Grokhovsky, 2006). A local increase in cleavage was observed at nucleotides adjacent to the sites where Pt-bis-netropsin pins were bound (wavy arrows). Similar regions where the cleavage rate decreased or increased depending on the conformation of Pt-bis-netropsin in complex with DNA sequences containing blocks of thymines or alternating adenines and thymines in one strand are detectable in Fig. 3 (lanes 5 - 7).

\section{Conclusion}

We have developed a new method for studying sequence-dependent structural dynamics of DNA fragments in solution. The approach is based on the analysis of ultrasound - induced DNA cleavage using high resolution denaturing polyacrylamide gel electrophoresis. Ultrasonic cleavage of DNA observed in our experiments represents mechanochemical reaction induced by cavitational processes in irradiated solution. It has been shown that the intensity of cleavage of sugar-phosphate backbone depends on the nucleotide sequence of irradiated fragments.

The computer methods for treatment and analysis of cleavage rate data have been developed along with several models for qualitative description of experimental effects. Based on recent data for structural and dynamical properties of DNA the interpretation of observed cleavage specificity has been offered.

As far as currently used methods for genome sequencing commonly use ultrasonic cleavage of the sample DNA and basically imply that this cleavage is non-specific, it is possible that the observed effect of sequence-dependence of DNA cleavage with ultrasound actually should be taken into account in order to avoid systematic errors during sequence assembly procedure.

Cleavage rates, i.e. the mean values of the relative intensities of cleavage of the central phosphodiester bond in all 16 dinucleotides and all 256 tetranucleotides, were determined by multivariate statistical analysis. We observed a remarkable enhancement of cleavage rates of phosphodiester bonds after deoxycytidine, which diminished in the following row of dinucleotides: $d(C p G)>d(C p A)>d(C p T)>>d(C p C)$. The cleavage rates for all pairs of complementary dinucleotides were significantly different from each other. The effect of flanking nucleotides in tetranucleotides on cleavage rates of all 16 types of central dinucleotides was also statistically significant. The sequence-dependent ultrasonic cleavage rates of dinucleotides are consistent with reported data on the intensity of the conformational motion of their 5'-deoxyribose. The sequence specificity of ultrasonic cleavage is the result of sequence-dependent conformational dynamics, and is likely modulated by the intensity of the sugar ring $S \leftrightarrow N$ interconversion. Sequence effects on conformational dynamics in any dinucleotide seem to propagate beyond mono and dinucleotide levels. Local conformational motions in complementary strands are independent (Grokhovsky et al., 2011).

Hence, the relative intensity of ultrasound cleavage may serve as indicator of sequencespecific flexibility in both strands of DNA. Each complementary chain can be characterized independently by the cleavage rate, and the diversity of conformational dynamics in both complementary chains can be estimated. Such numerical evaluation may be useful for identifying promoter regions in the genome and assessing preferences for nucleosome positioning. 


\section{Acknowledgment}

We thank Georgy Gursky and Victor Salyanov for their useful discussions about the paper.

This work was supported by the Program of the Presidium of the Russian Academy of Sciences on Molecular and Cell Biology, and the Russian Foundation for Basic Research (projects 11-04-02001a and 12-04-01584a).

\section{References}

Bailly C., Kluza J., Martin C., Ellis T. \& Waring M.J. (2005). DNase I footprinting of small molecule binding sites on DNA. Methods Mol. Biol., Vol. 288, pp. 319-342.

Belikov S., Wieslander L. (1995). Express protocol for generating G + A sequencing ladders. Nuclei Acids Res. Vol. 23, p. 310.

Belikov S. V., Grokhovsky S. L., Isaguliants M. G., Surovaya A. N. \& Gursky G. V. (2005). Sequence-specific minor groove binding ligands as potential regulators of gene expression in Xenopus laevis oocytes. J. Biomol. Struct. Dyn., Vol. 23, pp. 193-202.

Basedow A. M. \& E. B. Ebert. (1977). Ultrasonic degradation of polymers in solution. Advances in Polymers Science. A. Abe, A.-C. Albertsson \& J. Genzer, editors. Springer, Berlin/Heidelberg., Vol. 22, pp. 83-148.

Brukner I., Sánchez R., Suck D. \& Pongor S. (1995). Sequence-dependent bending propensity of DNA as revealed by DNase I: parameters for trinucleotides. EMBO J., Vol. 14, pp. 1812-1818.

Bullwinkle T.J. \& Koudelka G.B. (2011). The lysis-lysogeny decision of bacteriophage 933W: a 933W repressor-mediated long-distance loop has no role in regulating 933W PRM activity. The Journal of Bacteriology, Vol. 193, pp. 3313-3323.

Bustamante C., Smith S.B., Liphardt J. \& Smith D. (2000). Single-molecule studies of DNA mechanics. Curr. Opin. Struct. Biol. Vol. 10, pp. 279-285.

Crothers D.M. (1987). Gel electrophoresis of protein-DNA complexes. Nature, Vol. 325, pp. $464-465$.

Das R., Laederach A., Pearlman S. M., Herschlag D. \& Altman R. B. (2005). SAFA: semiautomated footprinting analysis software for high-throughput quantification of nucleic acid footprinting experiments. RNA, Vol. 11, pp. 344-354.

Didenko Y.T., McNamara W.B. \& Suslick K.S. (1999). Temperature of multibubble sonoluminescence in water. J. Phys. Chem. A. Vol. 103, pp. 10783-10788.

van Dyke M. W. \& Dervan P. B. (1983). Methidiumpropyl-EDTA*Fe(II) and DNase I footprinting report different small molecule binding site sizes on DNA. Nucleic Acids Research, Vol. 11, pp. 5555-5567.

Fagan P. \& D. E. Wemmer. (1992). Cooperative binding of distamycin-A to DNA in the 2:1 mode. J. Am. Chem. Soc. Vol. 114, pp. 1080-1081.

Greenbaum J.A., Pang B. \& Tullius T.D. (2007). Construction of a genome-scale structural map at single-nucleotide resolution. Genome Res., Vol. 17, pp. 947-953.

Grokhovsky S.L. \& Zubarev V.E. (1991). Sequence-specific cleavage of double-stranded DNA caused by X-ray ionization of the platinum atom in the Pt-bis-netropsin DNA complex. Nucl. Acids Res., Vol. 19, pp. 257-264.

Grokhovsky S.L., Gottikh B.P. \& Zhuze A.L. (1992). Ligands with affinity for certain DNA sequences: IX. Sythesis of netropsin and distamycin A analogs containing a 
sarcolysin residue or a platinum (II) atom. Bioorg. Khim. (Russ.), Vol. 18, pp. 570583.

Grokhovsky S. L., Nikolaev V. A., Zubarev V. E., Surovaya A. N., Zhuze A. L., Chernov B. K., Sidorova N. Yu., Zasedatelev A. S. \& Gursky G. V. (1992) Specific DNA Cleavage by a Netropsin Analog Containing a Copper(II)-Chelating Peptide GlyGly-His. Molecular Biology (Russ). VoL 26, pp. 839-858.

Grokhovsky S. L., Surovaya A. N., Burckhardt G., Pismensky V. F., Chernov B. K., Zimmer Ch. \& Gursky G. V. ( 1998). DNA sequence recognition by bis-linked netropsin and distamycin derivatives. FEBS Lett., Vol. 439, pp. 346-350.

Grokhovsky S. L. (2006). Specificity of DNA cleavage by ultrasound. Molecular Biology (Russ), Vol. 40, pp. (276-283).

Grokhovsky S. L., Il'icheva I. A., Nechipurenko D. Yu., Panchenko L. A., Polozov R. V. \& Nechipurenko Yu. D. (2008). Ultrasonic cleavage of DNA: quantitative analysis of sequence specificity. Biophysics (Russ.), Vol. 53, pp. 250-251.

Grokhovsky S. L., Il'icheva I. A., Nechipurenko D. Yu., Golovkin M. V., Panchenko L. A., Polozov R. V. \& Nechipurenko Y. D. (2011). Sequence-specific ultrasonic cleavage of DNA. Biophysical J., Vol. 100, pp. 117-125.

Gursky G.V., Zasedatelev A.S., Zhuze A.L., Khorlin A.A., Grokhovsky S.L., Streltsov S.A., Surovaya A.N., Nikitin S.M., Krylov A.S., Retchinsky V.O., Mikhailov M.V., Beabealashvili R.S. \& Gottich B.P. (1983). Synthetic sequence-specific ligands. Cold Spring Harbor Symp. Quant. Biol., Vol. 47, pp. 367-378.

Hogan M. E., Roberson M. W. \& Austin R. H. (1989). DNA flexibility variation may dominate DNase I cleavage. Proc. Natl. Acad. Sci. USA, Vol. 86, pp. 9273-9277.

Il'icheva I. A., Nechipurenko D. Yu. \& Grokhovsky S. L. (2009). Ultrasonic cleavage of nicked DNA. J. Biomol. Struct. Dyn., Vol. 27, pp. 391-398.

Kraev A.S. (1988). A simple system for phage M13 cloning and DNA sequencing with the use of terminators. Mol. Biol. (Russ.), Vol. 22, pp. 1164-1197.

Maniatis T., Fritsch E.F. \& Sambrook J. (1982). Molecular Cloning: A Laboratory Manual. Cold Spring Harbor, N.Y.: Cold Spring Harbor Lab. Press.

Margulis M. A. (1984). Osnovi Zvukohimii. Himiya, Moscow.

McNamara W.B., Didenko Y.T. \& Suslick K.S. (1999). Sonoluminescence temperatures during multibubble cavitation. Nature 401, pp. 772-775.

Nechipurenko D. Yu., Golovkin M. V., Nechipurenko Yu. D., Il'icheva I. A., Panchenko L. A., Polozov R. V. \& Grokhovsky S. L. (2009). Characteristics of ultrasonic cleavage of DNA. Journal of Structural Chemistry. (Russ.), Vol. 50, pp. 1007-1013.

Neidle S., Pearl L.H. \& Skelly J.V. (1987). DNA structure and perturbation by drug binding. Biochem. J., Vol. 243, pp. 1-13.

Nikolaev V.A., Grokhovsky S.L., Surovaya A.N., Leinsoo T.A., Sidorova N.Yu., Zasedatelev A.S., Zhuze A.L., Strachan G.A., Shafer R.H. \& Gursky G.V. (1996). Design of sequence-specific DNA-binding ligands that use two-stranded peptide motif for DNA sequence recognition. J. Biomol. Struct. Dyn., Vol. 14, pp. 31-47.

Parker S.C.J., Hansen L., Abaan H.O., Tullius T.D. \& Margulies E.H. (2009). Local DNA topography correlates with functional noncoding regions of the human genome. Science, Vol. 324, pp. 389-392.

Shadle S. E., Allen D. F., Guo H., Pogozelski W. K., Bashkin J. S. \& Tullius T. D. (1997). Quantitative analysis of electrophoresis data: novel curve fitting methodology and 
its application to the determination of a protein-DNA binding constant. Nucleic Acids Res., Vol. 25, pp. 850-860.

Spassky A. \& Angelov D. (1997). Influence of the local helical conformation on the guanine modifications generated from one-electron DNA oxidation. Biochemistry, Vol. 36, pp. 6571-6576.

Surovaya A.N., Burckhardt G., Grokhovsky S.L., Birch-Hirschfeld E., Gursky G.V. \& Zimmer Ch. Hairpin polyamides that use parallel and antiparallel side-by-side peptide motifs in binding to DNA. J. Biomol. Struct. Dyn. (1997). Vol. 14, pp. 595606.

Surovaya A.N., Burckhardt G., Grokhovsky S.L., Birch-Hirschfeld E., Nikitin A.M., Fritzsche H., Zimmer C. \& Gursky G.V. (2001). Binding of bis-linked netropsin derivatives in the parallel-stranded hairpin form to DNA. J. Biomol. Struct. Dyn., Vol. 18, pp. 689701.

Surovaya A.N., Grokhovsky S.L., Burkhardt H., Fritsche H., Zimmer K. \& Gursky G.V. (2002). Effect of local DNA conformation in bis-netropsin binding to DNA. Mol. Biol. (Russ), Vol. 36, pp. 901-911.

Surovaya A.N., Grokhovsky S.L., Bazhulina N.P. \& Gursky G.V. (2008), DNA-Binding Activity of Bis-Netropsin Containing a cis-Diaminoplatinum Group between Two Netropsin Fragments. Biophysica (Russ.), Vol. 53, pp. 344-351.

Suslick K.S. \& Price G.J. (1999). Applications of ultrasound to materials chemistry. Annu. Rev. Mater. Sci. Vol. 29, pp. 295-326.

Takamoto K., Chance M.R. \& Brenowitz M. (2004). Semi-automated, single-band peakfitting analysis of hydroxyl radical nucleic acid footprint autoradiograms for the quantitative analysis of transitions. Nucleic Acids Res., Vol. 32, No. 15, e119.

Tate W. P. \& Petersen G. B. (1975). Stability of pyrimidine oligodeoxyribonucleotides released during degradation of deoxyribonucleic acid with formic acid diphenylamine reagent. Biochem J., Vol. 147, pp. 439-445.

Tolstorukov M. Y., Jernigan R. L. \& Zhurkin V. B. (2004). Protein-DNA hydrophobic recognition in the minor groove is facilitated by sugar switching. J. Mol. Biol., Vol. 337, pp. 65-76.

Thomas J.R. (1959). Sonic degradation of high polymers in solution. J. Phys. Chem. 63, pp. 1725-1729.

Travers A. A. (2004). The structural basis of DNA flexibility. Phil. Trans. R. Soc. Lond. A, Vol. 362, pp. 1423-1438.

Tullius T.D. (1988). DNA footprinting with hydroxyl radical. Nature 332: 6165, pp 663-664.

Vtyurina N. N., Grokhovsky S. L., Filimonov I. V., Medvedkov O. I., Nechipurenko D. Yu., Vasiliev S. A. \& Nechipurenko Yu. D. (2011). Cleavage of DNA fragments induced by UV nanosecond laser excitation at 193 nm. Biofizika (Russ.), Vol. 56, pp. 399-402.

Waring M. J. (2006) Sequence-Specific DNA Binding Agents (M.J. Waring, ed.), Royal Society of Chemistry, Biomolecular Science series. $258 \mathrm{pp}$.

Wells R.D. (2009). Discovery of the role of non-B DNA structures in mutagenesis and human genomic disorders. The Journal of Biological Chemistry, Vol. 284, pp. 8997-9009.

Zar J. H. (1999). Biostatistical Analysis. Prentice Hall, Upper Saddle River, NJ.

Zimmer Ch. \& Wahnert U. (1986). Nonintercalating DNA-binding ligands: specificity of the interaction and their use as tools in biophysical, biochemical and biological investigations of the genetic material. Prog. Biophys. Mol. Biol. Vol. 47, pp. 31-112. 


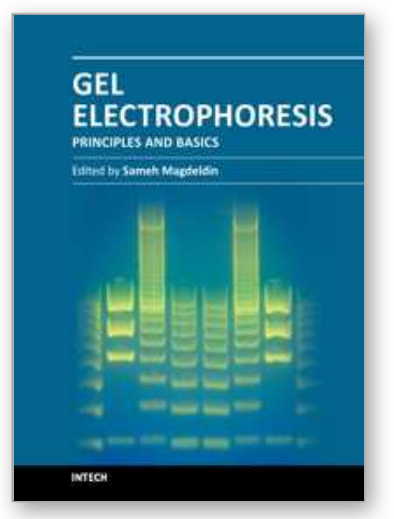

\author{
Gel Electrophoresis - Principles and Basics \\ Edited by Dr. Sameh Magdeldin
}

ISBN 978-953-51-0458-2

Hard cover, 346 pages

Publisher InTech

Published online 04, April, 2012

Published in print edition April, 2012

Most will agree that gel electrophoresis is one of the basic pillars of molecular biology. This coined terminology covers a myriad of gel-based separation approaches that rely mainly on fractionating biomolecules under electrophoretic current based mainly on the molecular weight. In this book, the authors try to present simplified fundamentals of gel-based separation together with exemplarily applications of this versatile technique. We try to keep the contents of the book crisp and comprehensive, and hope that it will receive overwhelming interest and deliver benefits and valuable information to the readers.

\title{
How to reference
}

In order to correctly reference this scholarly work, feel free to copy and paste the following:

Sergei Grokhovsky, Irina Il'icheva, Dmitry Nechipurenko, Michail Golovkin, Georgy Taranov, Larisa Panchenko, Robert Polozov and Yury Nechipurenko (2012). Quantitative Analysis of Electrophoresis Data Application to Sequence-Specific Ultrasonic Cleavage of DNA, Gel Electrophoresis - Principles and Basics, Dr. Sameh Magdeldin (Ed.), ISBN: 978-953-51-0458-2, InTech, Available from:

http://www.intechopen.com/books/gel-electrophoresis-principles-and-basics/quantitative-analysis-ofelectrophoresis-data-application-to-sequence-specific-ultrasonic-cleavage-o

\section{INTECH}

open science | open minds

\section{InTech Europe}

University Campus STeP Ri

Slavka Krautzeka 83/A

51000 Rijeka, Croatia

Phone: +385 (51) 770447

Fax: +385 (51) 686166

www.intechopen.com

\section{InTech China}

Unit 405, Office Block, Hotel Equatorial Shanghai

No.65, Yan An Road (West), Shanghai, 200040, China

中国上海市延安西路65号上海国际贵都大饭店办公楼 405 单元

Phone: +86-21-62489820

Fax: $+86-21-62489821$ 
(C) 2012 The Author(s). Licensee IntechOpen. This is an open access article distributed under the terms of the Creative Commons Attribution 3.0 License, which permits unrestricted use, distribution, and reproduction in any medium, provided the original work is properly cited. 